\title{
Observations of static strain-aging in polycrystalline NiAl
}

\author{
M. L. Weaver, ${ }^{a}$ R. D. Noebe, ${ }^{b}$ J. J. Lewandowski, ${ }^{c}$ B. F. Oliver ${ }^{d}$ \& M. J. Kaufman ${ }^{e}$ \\ ${ }^{a}$ Center for Nonlinear and Nonequilibrium Aeroscience, Florida A\&M University, Tallahassee, Florida 32310, USA and Department \\ of Mechanical Engineering, FAMU/FSU College of Engineering, Florida A\&M University/Florida State University, Tallahassee, \\ Florida 32310, USA \\ ${ }^{b} N A S A$ Lewis Research Center, Cleveland, Ohio 44135, USA \\ ${ }^{c}$ Department of Materials Science \& Engineering, Case Western Reserve University, Cleveland, Ohio 44I06, USA \\ ${ }^{d}$ Department of Materials Science \& Engineering, University of Tennessee, Knoxville, Tennessee 37996, USA \\ ${ }^{\circ}$ Department of Materials Science \& Engineering, University of Florida, Gainesville, Florida 32611, USA
}

(Received 29 January 1996; accepted 2 February 1996)

\begin{abstract}
Static strain-aging has been investigated in eight polycrystalline NiAl alloys. After annealing at $1100 \mathrm{~K}$ for $7200 \mathrm{~s}$ followed by furnace cooling, high-purity, nitrogen-doped, and titanium-doped alloys exhibited continuous yielding, while conventional-purity and carbon-doped alloys exhibited distinct upper yield points and Lüders strains. Either water quenching from $1100 \mathrm{~K}$ or prestraining via hydrostatic pressurization suppressed the yield points in the latter alloys, but they could be reintroduced by further annealing treatments. Yield points could be re-introduced more rapidly if the specimens were prestrained uniaxially rather than hydrostatically, owing to the arrangement of dislocations into cell structures during uniaxial deformation. Chemical analysis suggests that the species responsible for strain-aging is interstitial carbon. Copyright $\mathbb{C} 1996$ Elsevier Science Limited
\end{abstract}

Key words: A. nickel aluminides, based on TiAl B. mechanical properties at ambient temperature, microalloying, strain-aging, yield stress.

\section{INTRODUCTION}

Body-centered cubic (BCC) metals and alloys exhibit an extreme sensitivity to minute additions of interstitials which can lead to strain-aging phenomena. Not surprisingly, several aspects of strain-aging have also been identified as playing a role in the deformation of polycrystalline and single crystal B2 NiA1. They are the occurrence of yield stress plateaus as a function of temperature, yield points, strain-rate sensitivity minima, serrated stress-strain curves, and flow stress transients after changes in strain-rate. ${ }^{1-21}$ Extensive work by Margevicius et al. ${ }^{6,19-21}$ has shown that a sharp yield point can occur in binary $\mathrm{NiAl}$ following annealing at $1100 \mathrm{~K}$ and furnace cooling. This yield point can be suppressed by subsequent prestraining of the material by hydrostatic pressurization prior to testing, and it can be recovered by aging the prestrained material for 7200 s, (i.e. 2 h) at $673 \mathrm{~K}$. Similarly, Pascoe and Newey ${ }^{10}$ observed the formation of room temperature yield points in near stoichiometric $\mathrm{NiAl}$ annealed for $3600 \mathrm{~s}(1 \mathrm{~h})$ at $350 \mathrm{~K}$ following a uniaxial prestrain. In addition, preliminary investiga- tions by Weaver et al. ${ }^{13}$ have shown that these yield points can be suppressed by water quenching from high temperature as opposed to furnace cooling. Despite these observations, no complete investigation of the interrelated effects of interstitial content, annealing and prestrain on mechanical behavior has been conducted on NiAl. Consequently, the purpose of this document is to provide a more thorough description of the combined effects of interstitial content, annealing and prestrain on the tensile flow and fracture behavior of polycrystalline NiAl.

\section{EXPERIMENTAL DETAILS}

\section{Material}

$\mathrm{NiAl}$ alloys in the form of: (1) one titanium doped vacuum induction melted (VIM) ingot (NiAl-Ti); (2) two conventional purity (CPNiAl-1, CPNiAl-2) ingots; (3) two carbon doped castings with varying carbon and oxygen concentrations (NiAl100C and NiAl-300C); (4) two low interstitial 
high-purity zone refined ingots, one of which was subsequently zone leveled with carbon (HP-NiAl and $\mathrm{HPNiAl}-\mathrm{C}$ respectively); and (5) a nitrogenatomized powder $(\mathrm{NiAl}-\mathrm{N})$ were the basic starting materials used in this investigation. All were extruded at $1200 \mathrm{~K}$ at either a $12: 1$ or $16: 1$ reduction ratio. Descriptions of the equipment and processes used to fabricate the high purity, zone leveled and nitrogen doped alloys are presented elsewhere. ${ }^{22-24}$

\section{Material characterization}

Chemical analyses of the eight extrusions were conducted using the techniques deemed to be the most accurate for the particular elements. The results of these analyses are presented in Table 1 along with the post extrusion grain sizes obtained using the linear intercept method.

Optical microscopy, scanning electron microscopy (SEM) and transmission electron microscopy (TEM) were used to assess the microstructure of the materials. Polished optical microscopy specimens were etched by swabbing with a mixture of $0.10 \mathrm{~kg}$ $\mathrm{MoO}_{3}, 50 \mathrm{ml} \mathrm{HF}$ and $150 \mathrm{ml} \mathrm{H}_{2} \mathrm{O}$.

Samples for transmission electron microscopy (TEM) were cut from the gages of tested tensile specimens with a low-speed diamond saw and twin jet-electropolished in a solution of $70 \%$ ethanol, $14 \%$ distilled water, $10 \%$ butylcellusolve and $6 \%$ perchloric acid at $273 \mathrm{~K}, 20-25 \mathrm{~V}$ and $0.15 \mathrm{~mA}$. TEM examinations were conducted in either a JEOL $100 \mathrm{CX}$ or a Philips EM420 microscope operating at accelerating voltage of $120 \mathrm{kV}$.

Fracture surfaces of selected tensile samples were examined using a Cambridge 200 scanning electron microscope. Quantitative fractography was performed to determine the percentage of intergranular fracture for most alloys. This was accomplished by taking at least five random micrographs of appropriate magnification relative to the grain size from each test specimen and using a point counting technique.

\section{Mechanical testing}

Round button-head tensile specimens were ground from the extruded rods so that the gage lengths of the samples were parallel to the extrusion direction. Sample dimensions were $3.1 \mathrm{~mm}$ for the tensile gage diameters and $30.0 \mathrm{~mm}$ for the tensile gage lengths. Prior to testing, all samples were electropolished in a $10 \%$ perchloric acid $90 \%$ methanol solution that was cooled to $208 \mathrm{~K}$. Tensile tests were performed on an Instron Model 1125 load frame at a constant crosshead velocity corresponding to an initial strain-rate, $\dot{\varepsilon}$, of $1.4 \times 10^{-4} \mathrm{~s}^{-1}$. All tests were performed in air at $300 \mathrm{~K}$. True stress-strain data were calculated from the load-time plots and

Table 1. Compositions and grain sizes of the polycrystalline NiAl alloys investigated

\begin{tabular}{|c|c|c|c|c|c|c|c|c|c|}
\hline \multirow{2}{*}{$\begin{array}{l}\text { Alloy } \\
\text { (heat) }\end{array}$} & \multirow{2}{*}{$\begin{array}{c}\text { Grain } \\
\text { size } \\
(\mu \mathrm{m})\end{array}$} & \multicolumn{4}{|c|}{$\mathrm{At} \%$} & \multicolumn{4}{|c|}{ Atppm } \\
\hline & & $\mathrm{Ni}$ & $\mathrm{Al}$ & $\mathrm{Ti}$ & $\mathrm{Si}$ & $\mathrm{C}$ & $\mathrm{O}$ & $\mathbf{N}$ & $\mathrm{S}$ \\
\hline $\begin{array}{l}\text { CPNiAl-1 } \\
\text { (L2971) }\end{array}$ & $18 \cdot 7 \pm 1 \cdot 5$ & $50 \cdot 1 \pm 0 \cdot 2$ & $49 \cdot 7 \pm 0 \cdot 2$ & - & 0.15 & 147 & $70^{*}$ & $<9$ & $<7$ \\
\hline $\begin{array}{l}\text { CPNiAl-2 } \\
\text { (L3199) }\end{array}$ & $18 \cdot 0 \pm 2 \cdot 0$ & $50 \cdot 1 \pm 0 \cdot 2$ & $49 \cdot 8 \pm 0 \cdot 2$ & - & 0.02 & 186 & 94 & $<9$ & $<7$ \\
\hline $\begin{array}{l}\text { HP-NiAl } \\
\text { (L2987) }\end{array}$ & $51 \cdot 4 \pm 2 \cdot 3$ & $49 \cdot 9 \pm 0 \cdot 2$ & $50 \cdot 1 \pm 0 \cdot 2$ & - & 0.02 & 43 & 32 & $<9$ & $<7$ \\
\hline $\begin{array}{l}\text { HPNiAl-C } \\
\text { (L,2988) }\end{array}$ & $44 \cdot 6 \pm 4 \cdot 0$ & $50 \cdot 2 \pm 0 \cdot 2$ & $49 \cdot 8 \pm 0 \cdot 2$ & - & 0.05 & 92 & 30 & $<9$ & $<7$ \\
\hline $\begin{array}{l}\text { NiAl-N } \\
\text { (P1810) }\end{array}$ & $4 \cdot 0 \pm 0 \cdot 3$ & $50 \cdot 1 \pm 0 \cdot 2$ & $49 \cdot 7 \pm 0 \cdot 2$ & - & 0.02 & 57 & 347 & 904 & $<7$ \\
\hline $\begin{array}{l}\text { NiAl-100C } \\
\text { (L3218) }\end{array}$ & $20 \cdot 0 \pm 2 \cdot 0$ & $49 \cdot 9 \pm 0 \cdot 2$ & $-50 \cdot 0 \pm 0 \cdot 2$ & - & 0.02 & 490 & 183 & $<9$ & $<13$ \\
\hline $\begin{array}{l}\text { NiAl-300C } \\
\text { (L3217) }\end{array}$ & $20 \cdot 0 \pm 2 \cdot 0$ & $49 \cdot 9 \pm 0 \cdot 2$ & $50 \cdot 0 \pm 0 \cdot 2$ & - & 0.01 & 1153 & 131 & $<9$ & $<12$ \\
\hline $\begin{array}{l}\text { NiAl-Ti } \\
\text { (L3215) }\end{array}$ & $20 \cdot 0 \pm 2 \cdot 0$ & $49 \cdot 9 \pm 0 \cdot 2$ & $50 \cdot 0 \pm 0 \cdot 2$ & 0.03 & 0.00 & 214 & 113 & 15 & $<7$ \\
\hline
\end{tabular}

$\mathrm{Ni}$ and $\mathrm{Al}$ : Analysis performed using wet chemistry/titration techniques, relative accuracy $\pm 1 \%$.

$\mathrm{C}$ and S: Analysis performed on a simultaneous carbon/sulfur determinator, LECO Corp., Model CS-244, relative accuracy $\pm 10 \%$.

$\mathrm{N}$ and $\mathrm{O}:$ Analysis performed on a simultaneous nitrogen/oxygen determinator, LECO Corp., Model TC-136 or Model TC-436, relative accuracy $\pm 10 \%$.

Ti: Analysis performed using inductively coupled plasma emission spectroscopy, relative accuracy $\pm 5 \%$.

Si: $\quad$ Analysis performed on an ultraviolet/visible spectrophotometer, Shimadzu, Model UV-160, relative accuracy $\pm 10 \%$.

*: $\quad$ The figure of 550 atppm quoted in earlier papers was in error. 
yield stresses were determined by the $0.2 \%$ offset method.

The tensile testing was accomplished in three steps:

First, baseline mechanical properties were determined for all eight alloys by testing them as follows: (1) as-extruded and (2) as-extruded $+1100 \mathrm{~K} / 7200$ s/furnace cool (FC). (3) Four alloys (CPNiAl-1, HP-NiAl, HPNiAl-C, and $\mathrm{NiAl-N}$ ), having received treatment (2), were prestrained via hydrostatic pressurization to $1.4 \mathrm{GPa}$. The prestrain pressurization treatment was selected based on the observations of Margevicius et al. ${ }^{6,19-21}$

Second, the temperature regime resulting in the maximum recovery of the yield point was determined for a series of CP-NiAl specimens, having received treatment (3). Specimens were annealed at temperatures ranging from 500 to $1100 \mathrm{~K}$ for times ranging between $60 \mathrm{~s}$ and $604800 \mathrm{~s}(168 \mathrm{~h})$ followed by $\mathrm{FC}$, air cooling (AC), or water quenching (WQ).

Third, some specimens were statically strain aged as follows: specimens were prestrained approximately $0.2 \%$ in tension at room temperature, unloaded, aged in situ on the load frame for aging times varying between $50 \mathrm{~s}$ and $113000 \mathrm{~s}(30 \mathrm{~h})$, and then restrained at room temperature to approximately $0.2 \%$. Aging temperatures were selected based on the results from the test sequences described above. On several occasions, specimens were subjected to recovery anneals of $1100 \mathrm{~K} / 1800 \mathrm{~s}(30$ min.)/AC following an aging cycle. These procedures were repeated several times until fracture occurred in an effort to elucidate the influence of strain-aging on flow and fracture behavior of $\mathrm{NiAl}$. The results of one such experiment are presented in Fig. 1, which shows the stress-strain curves for an alloy following multiple strain-aging cycles. A more detailed accounting of the test method used to study static strain-aging in $\mathrm{NiAl}$ is provided in refs 12,13 and 15 .

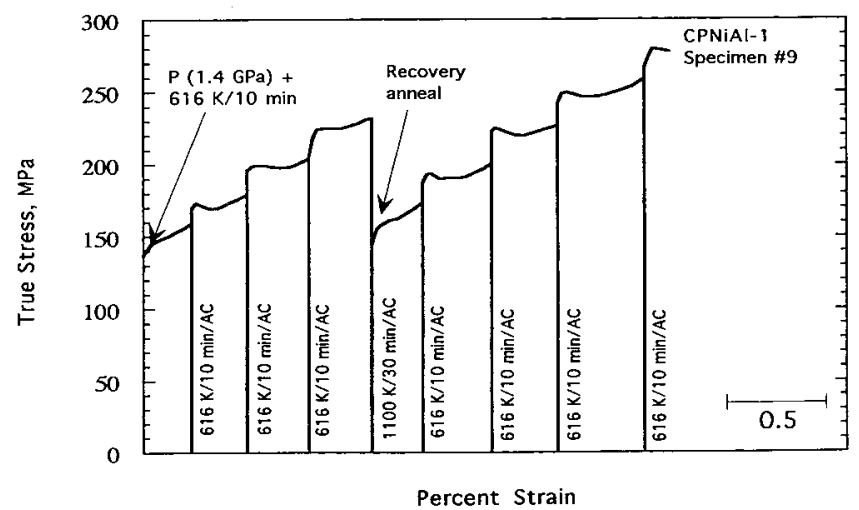

Fig. 1. Series of true stress-strain curves for CP-NiAl after multiple strain-aging cycles.

\section{EXPERIMENTAL RESULTS}

\section{Composition and microstructure}

Within experimental accuracy $( \pm 0.2$ at $\%$ for $\mathrm{Ni}$ and $\mathrm{Al}$ ), the $\mathrm{Ni}$ and $\mathrm{Al}$ contents of the eight alloys are not significantly different from each other. The major differences between the materials are the residual $\mathrm{Si}, \mathrm{C}, \mathrm{O}$ and $\mathrm{N}$ contents and the presence of $\mathrm{Ti}$ as an alloying addition to $\mathrm{NiAl}-\mathrm{Ti}$.

The microstructures of all the $\mathrm{NiAl}$ alloys were similar as observed by optical microscopy and TEM, and consisted of fully dense, recrystallized and equiaxed grains. The only differences were the observation of semi-continuous distributions of nanometer-size precipitates in the $\mathrm{NiAl}-\mathrm{N}$ (see ref. 24) and $\mathrm{NiAl}-\mathrm{Ti}$ alloys, (Fig. 2). In the case of NiAl-N, previous studies have revealed that the precipitates are AlN. ${ }^{24}$ Energy dispersive spectroscopic (EDS)
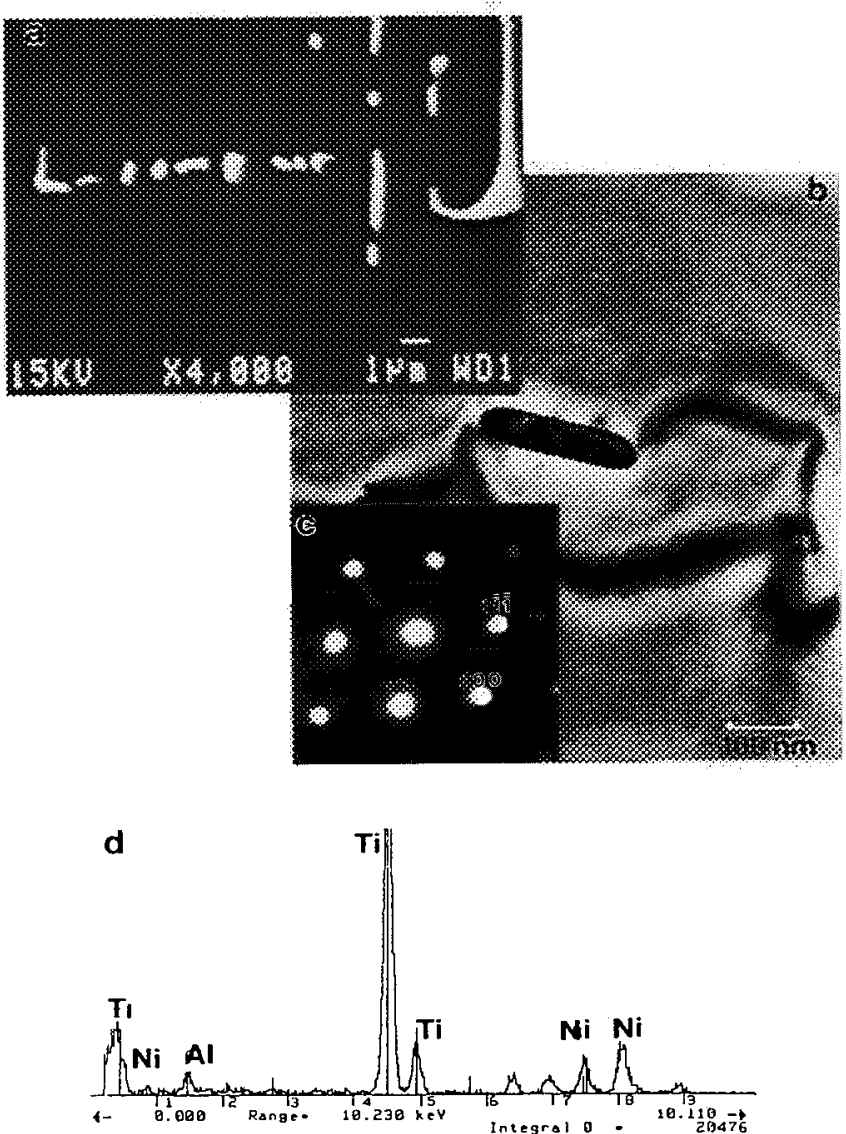

Fig. 2. Precipitates observed in NiAl-Ti: (a) backscattered scanning electron micrograph of $\mathrm{TiC}$ precipitates in $\mathrm{NiAl}-\mathrm{Ti}$; (b) BFTEM micrograph of a large TiC precipitate; (c) TEM microdiffraction pattern from the TiC precipitate $([00 \overline{1}] \mathrm{TiC}$ zone axis); and (d) EDS spectra for the particle in (c) indicating the presence of $\mathrm{Ti}$. 
analysis in the TEM indicated that the precipitates in NiAl-Ti were rich in Ti. The individual precipitates were, in general, too fine for analysis. On occasion, however, larger precipitates were observed within individual grains or along grain boundaries. These precipitates were typically elongated in shape as indicated in Fig. 2. Low-intensity EDS peaks corresponding to carbon were detected for some of these precipitates in addition to the distinct Ti peaks. Careful analysis of TEM microdiffraction patterns taken from these larger particles indicated that they were crystallographically consistent with TiC.

\section{Mechanical properties}

The baseline mechanical properties are summarized in Table 2. Typical room-temperature stress-strain curves for each alloy are shown in Figs 3-7. From this data it is observed that the yield stress of each alloy decreased following the $1100 \mathrm{~K} / 7200 \mathrm{~s} / \mathrm{FC}$ anneal. In addition, a tendency for discontinuous yielding was apparent in the CPNiAl-1, CPNiAl-2, HPNiAl-C, NiAl-100C and NiAl-300C alloys but not in HP-NiAl, NiAl-N or in NiAl-Ti. Further decreases in yield stress and elimination of the tendency for discontinuous yielding were achieved

Table 2. Baseline tensile properties of NiAl alloys

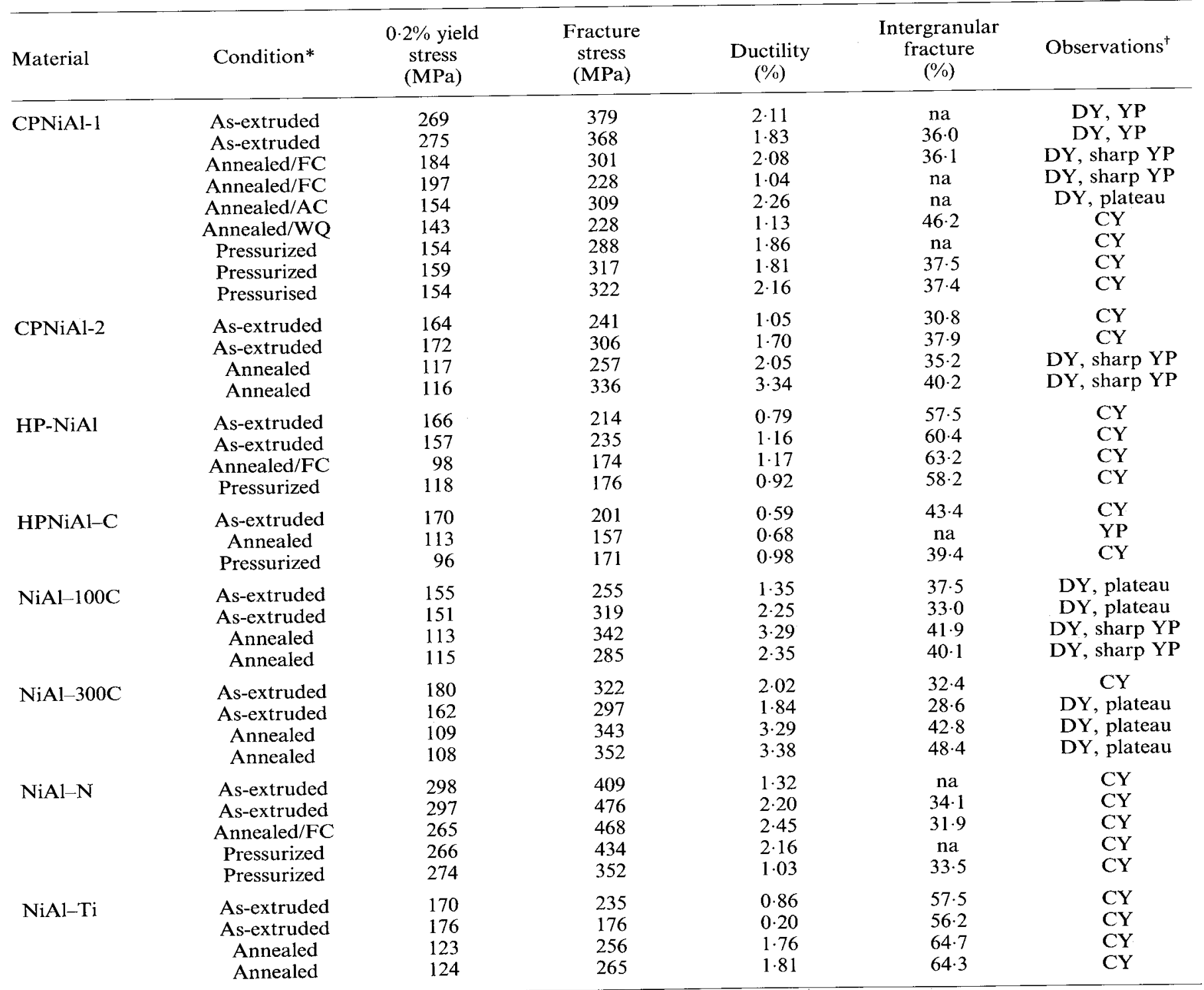

*Annealed $/ \mathrm{FC}$ or annealed $=$ as-extruded $+1100 \mathrm{~K} / 7200 \mathrm{~s} / \mathrm{FC} ;$ Annealed $/ \mathrm{AC}=$ as-extruded $+1100 \mathrm{~K} / 7200 \mathrm{~s} / \mathrm{AC} ; \mathrm{Annealed} / \mathrm{WQ}$ $=$ as-extruded $+1100 \mathrm{~K} / 7200 \mathrm{~s} / \mathrm{WQ}$; Pressurized = as-extruded $+1100 \mathrm{~K} / 7200 \mathrm{~s} / \mathrm{FC}+$ pressurize $1.4 \mathrm{GPa}$.

${ }^{\dagger} \mathrm{DY}=$ discontinuous yielding, upper yield point, sharp yield drop; $\mathrm{YP}=$ yield point; $\mathrm{CY}=$ continuous yielding; na $=$ not available. Intergranular fracture: accuracy $= \pm 10 \%$. 


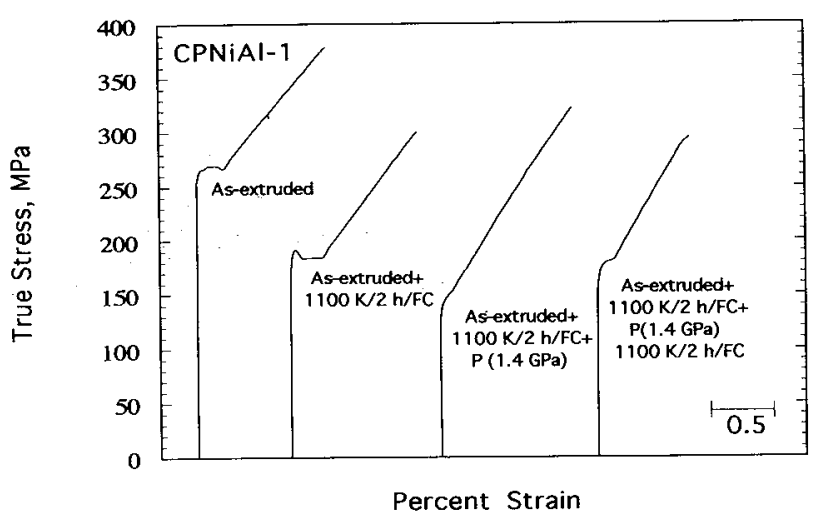

Fig. 3. Room-temperature tensile stress-strain curves for CPNiAl-1 in the as-extruded, annealed, pressurized and pressurized +annealed conditions.

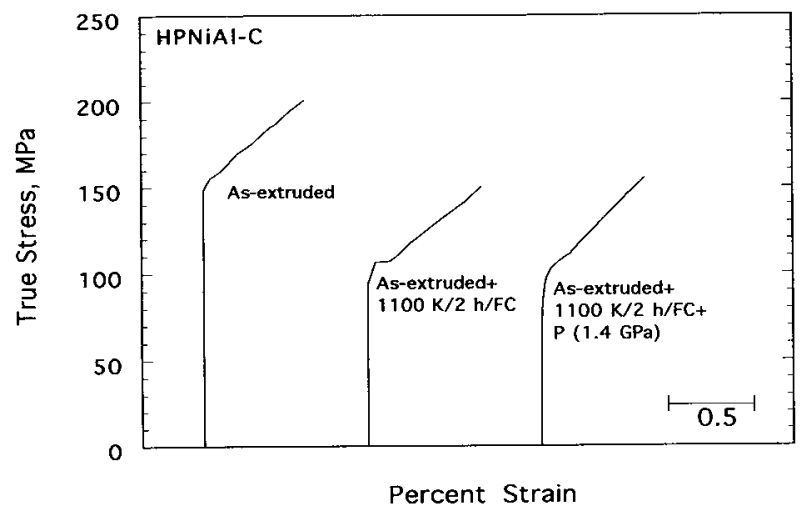

Fig. 4. Room-temperature tensile stress-strain curves for HPNiAl-C in the as-extruded, annealed, and pressurized conditions.

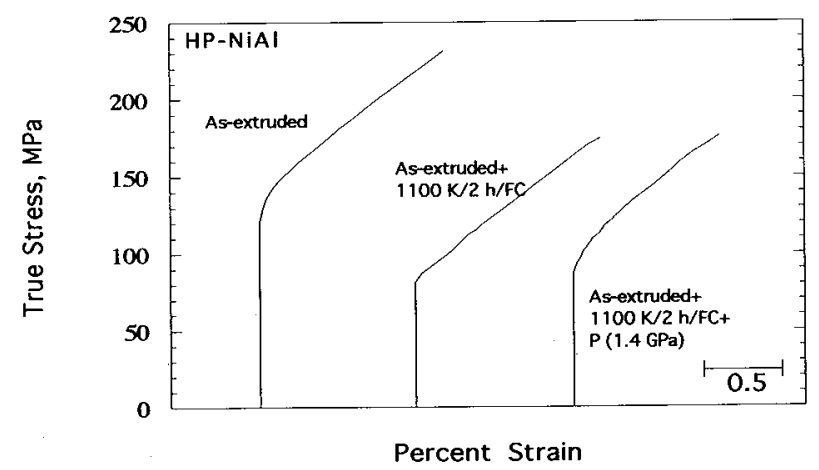

Fig. 5. Room-temperature tensile stress-strain curves for HP$\mathrm{NiAl}$ in the as-extruded, annealed, and pressurized conditions.

in the CPNiAl-1 and HPNiAl-C alloys if the specimens were subsequently hydrostatically pressurized at $1.4 \mathrm{GPa}$, whereas no additional decreases in yield stress or other apparent changes in flow behavior were observed in the powder processed NiAl-N alloy or in the HP-NiAl material after hydrostatic pressurization (Figs 3-6). Pressurization treatments were not conducted on the remaining alloys.

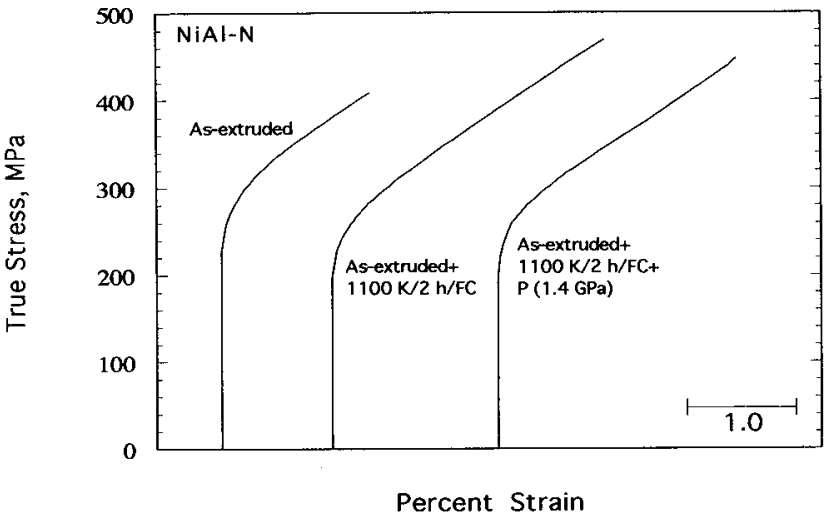

Fig. 6. Room-temperature tensile stress-strain curves for $\mathrm{NiAl}-\mathrm{N}$ in the as-extruded, annealed, and pressurized conditions.

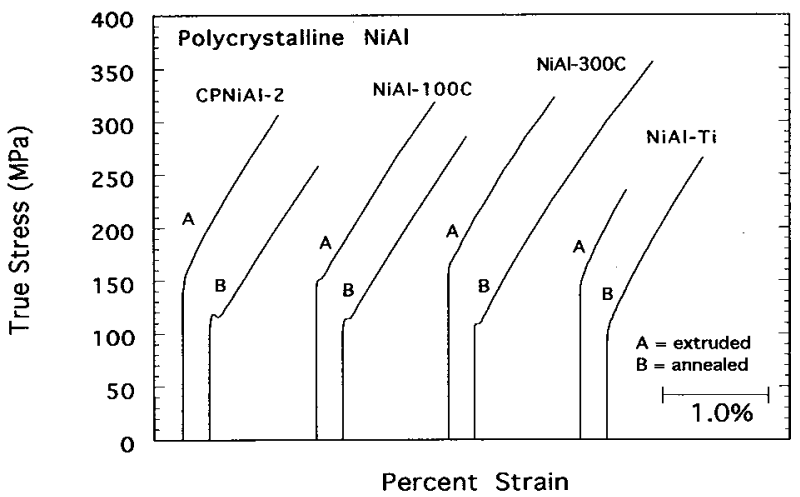

Fig. 7. Representative room-temperature tensile stress-strain curves for CPNiAl-2, NiAl-100C, NiAl-300C and NiAl-Ti.

Recovery of the discontinuous yield behavior (in those alloys where such behavior was observed) following pressurization could be accomplished by re-annealing pressurized specimens at $1100 \mathrm{~K} / 2 \mathrm{~h}$ followed by furnace cooling (Fig. 4). Interestingly, even though the yield stress could be reduced by annealing and in some cases by hydrostatic pressurization, these treatments had no obvious influence on the tensile ductility or fracture behavior of the various alloys (Table 2). Similar observations have been recently reported by Margevicius and Lewandowski for single crystal and polycrystalline $\mathrm{NiAl}$ alloys. ${ }^{25}$ Representative scanning electron micrographs of the typical fracture surfaces observed in this study are exhibited in Fig. 8 and the percentage of intergranular fracture for all materials is summarized in Table 2 . For all specimens, failure was always by a combination of intergranular separation and transgranular cleavage. Surprisingly, the $\mathrm{HP}-\mathrm{NiAl}$ and NiAl$\mathrm{Ti}$ exhibited a greater tendency for intergranular failure and lower tensile ductility than the other alloys. 

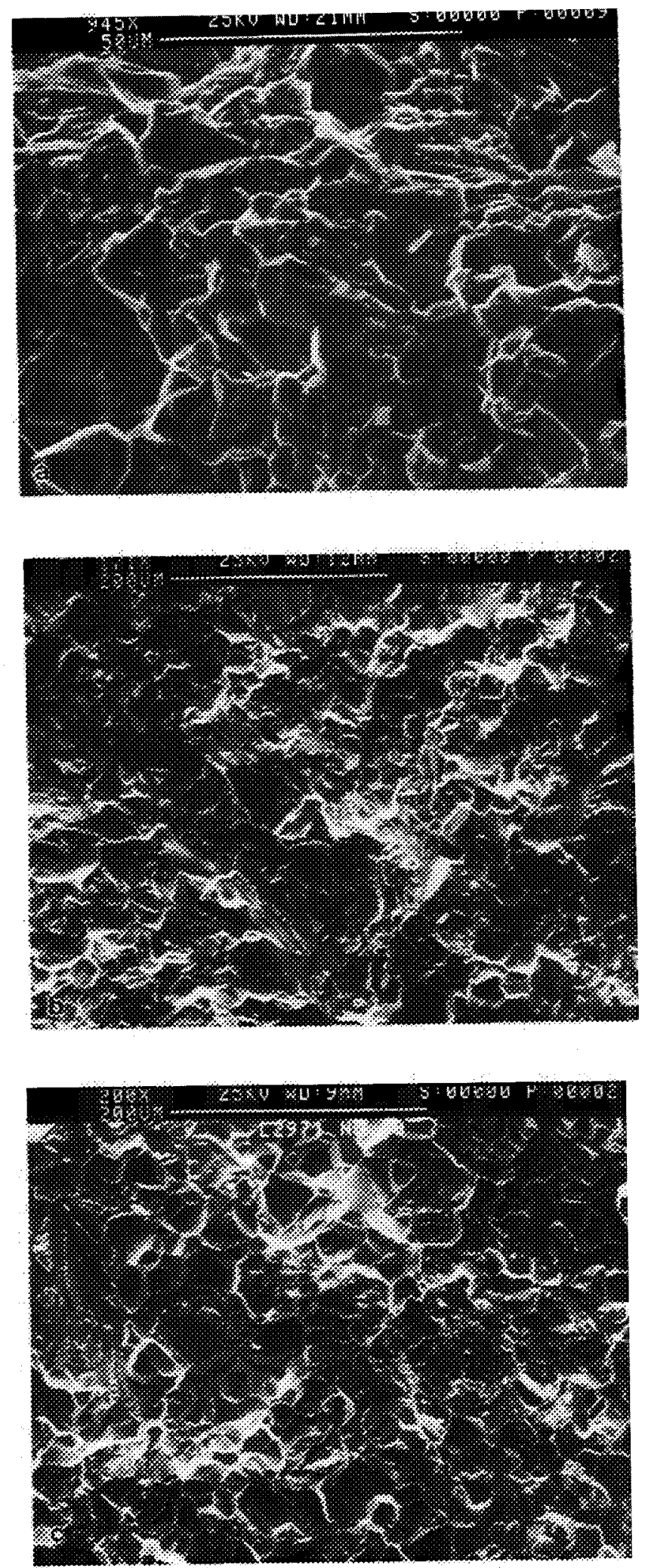

Fig. 8. Representative fracture surfaces of CPNiAl-1 samples tensile tested at room temperature: (a) as-extruded; (b) after annealing at $1100 \mathrm{~K}$ for $2 \mathrm{~h}$ followed by furnace cooling; (c) after annealing followed by subsequent pressurization. Similar fracture surfaces were observed in the other alloys tested in this study.
Influence of prestraining and annealing on baseline properties

To determine whether the observed yield points resulted from the hold at temperature or during cooling from the annealing temperature, specimens of CPNiAl-1 previously prestrained hydrostatically, were annealed at $1100 \mathrm{~K} / 7200 \mathrm{~s}$ followed by $\mathrm{AC}$ or WQ. The resulting properties are summarized in Fig. 9 and in Table 2 . After WQ, only continuous yielding was observed while after AC, there was some evidence of a yield plateau which initially suggests that the yield points observed following $\mathrm{FC}$ are the result of the pinning of dislocations by mobile solute atoms during cooling through lower temperatures. As a result, annealing experiments were initiated at lower temperatures to determine the critical temperature for the migration of solute atoms to dislocations. The results of these experiments are summarized in Fig. 10. It was observed that yield plateaus formed in CP-NiAl after hydrostatic prestraining followed by annealing

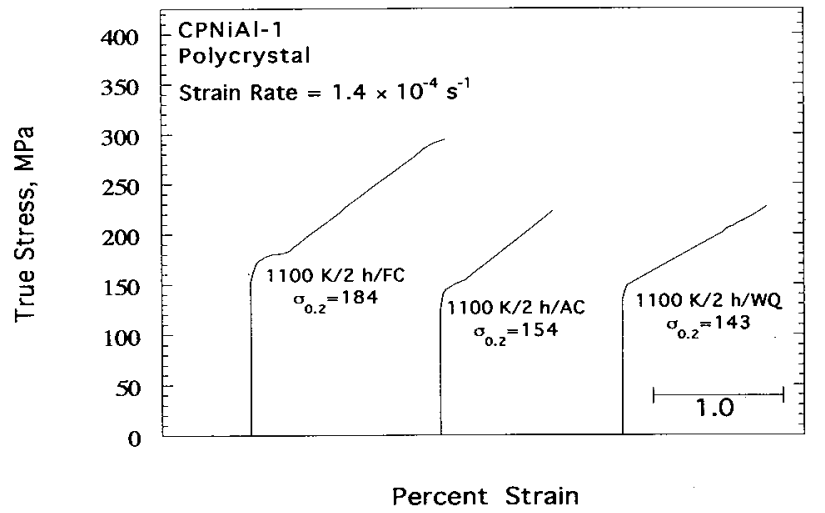

Fig. 9. Room-temperature stress-strain curves illustrating the influence of cooling rate on the tensile flow behaviour of CP-NiAl.

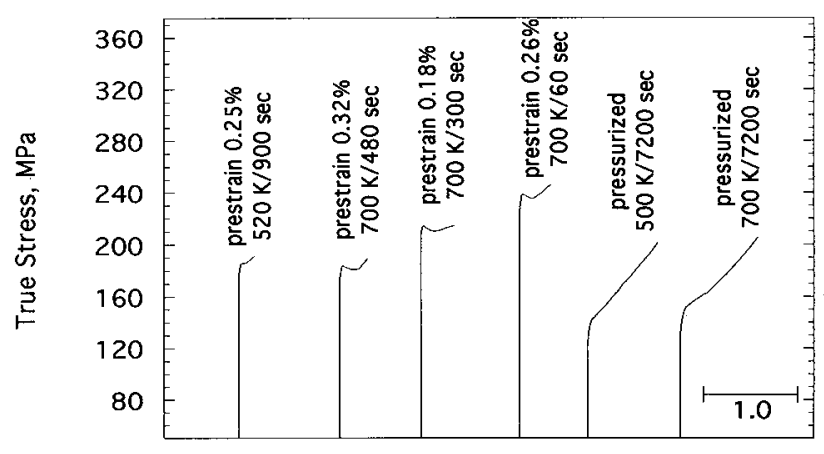

Percent Strain

Fig. 10. Room-temperature stress-strain curves illustrating the influence of various prestraining and annealing treatments on the tensile flow behavior of CP-NiAl. 
treatments of $700 \mathrm{~K} / 7200 \mathrm{~s} / \mathrm{FC}$ but not following anneals of $500 \mathrm{~K} / 7200 \mathrm{~s} / \mathrm{FC}$. Conversely, if the specimens were prestrained uniaxially, notable yield points formed readily after as little as $900 \mathrm{~s}$
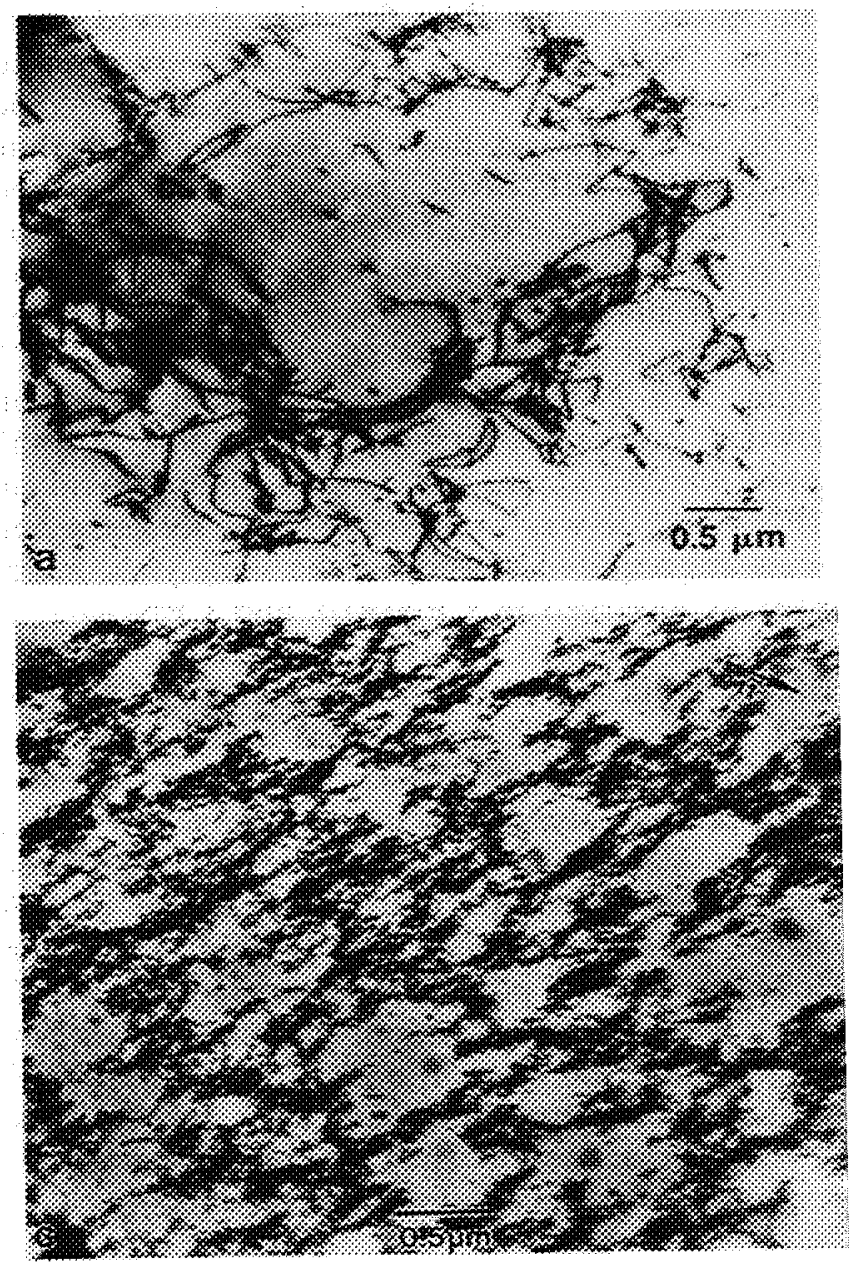

$(15 \mathrm{~min})$ at $522 \mathrm{~K}$ and in as little as $60 \mathrm{~s}(1 \mathrm{~min})$ at $700 \mathrm{~K}$. Additionally, no yield points were observed when annealing temperatures exceeded $900 \mathrm{~K}$.
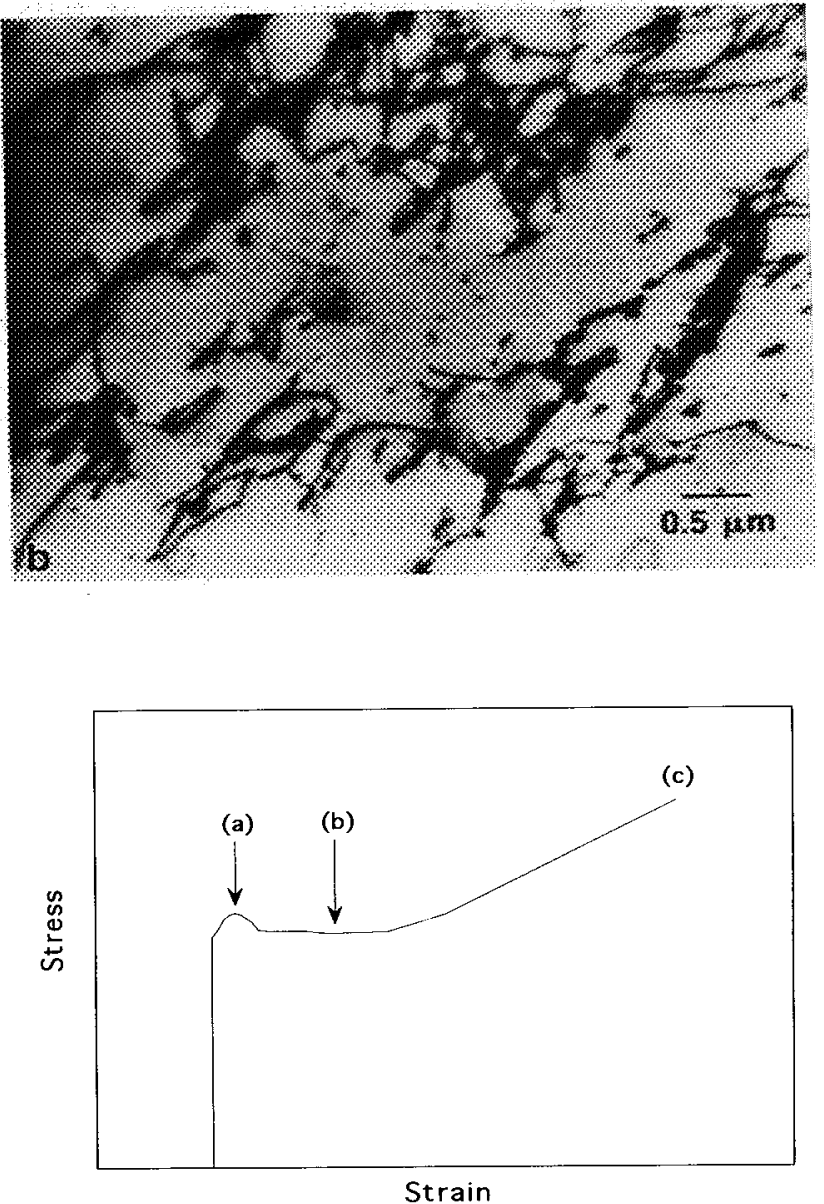

(d)

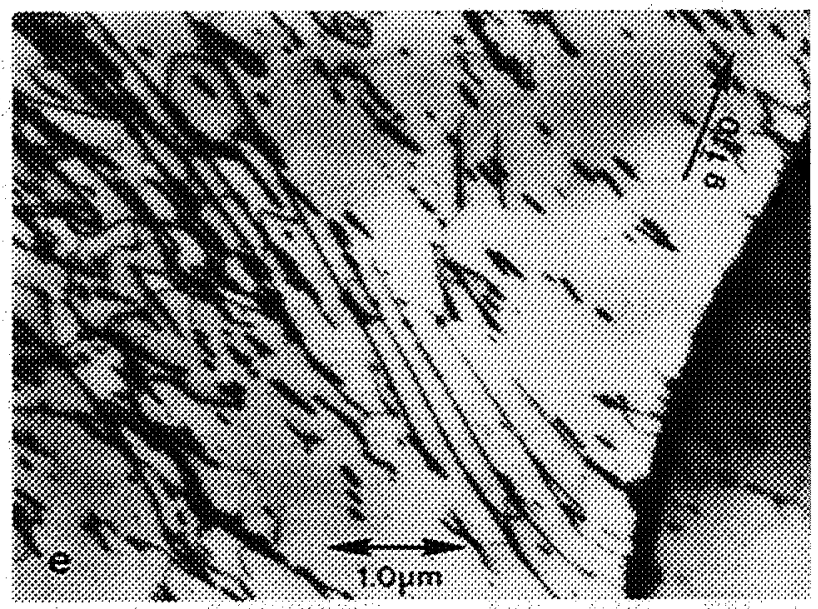

Fig. 11. Transmission electron micrographs of CPNiAl-1 after uniaxial and hydrostatic prestraining at $300 \mathrm{~K}$ : (a) $\mathrm{CPNiAl-1}$ prestrained uniaxially $0.05 \%$; (b) CPNiAl-1 prestrained uniaxially $0.40 \%$; (c) CPNiAl-1 prestrained uniaxially 2.04\%; (d) schematic stress-strain curve showing stress-strain levels where specimens in (a)-(c) were taken from; (e) prestrained hydrostatically to $1.4 \mathrm{GPa}$. 


\section{TEM observations of deformed specimens}

Figure 11 shows a series of TEM bright field images of CPNiAl-1 that was deformed at room-temperature following anneals of $1100 \mathrm{~K} / 2 \mathrm{~h} / \mathrm{FC}$. Tensile tests were interrupted at plastic strains of 0.05 , 0.31 and $2.04 \%$ corresponding to the yield stress peak, the Lüders region and after fracture respectively. At 0.05 and $0.31 \%$ strain (Figs 11(a) and (b)), the dislocation structure consisted of a low density of inhomogeneously distributed dislocations arranged into poorly defined cells and dense tangles. Some intercellular/inter-tangle dislocation debris was observed although the cell interiors remained largely dislocation free. As the strain was increased to $2.04 \%$ (Fig. 11 ), the dislocation density increased and the cells were well defined. The dislocations observed were predominantly $<100>$ dislocations of mixed character. The predominant slip plane was $\{011\}$ although some dislocation debris lying on $\{001\}$ slip planes was occasionally detected.

Figure 11(e) shows the dislocation substructure observed in CPNiAl-1 following hydrostatic prestraining to $1.4 \mathrm{GPa}$. In agreement with the reports of Margevicius and co-workers ${ }^{20,21}$ for conventional purity cast and extruded $\mathrm{NiAl}$, the dislocation substructures consisted of a more uniform distribution of long, straight dislocations generated from grain boundaries. Diffraction contrast analysis revealed that all of the dislocations were of $<100>$ type.

In agreement with the many prior studies of extruded near-stoichiometric NiAl in bulk form ${ }^{26-28}$ and during in situ TEM observations, ${ }^{29}$ the deformation substructure following straining at room-temperature consisted of a network of poorly defined dislocation cells, dense tangles and intercellular debris. Well defined deformation bands were not observed by TEM nor was there evidence of coarse slip bands intersecting the specimen surfaces.

\section{DISCUSSION}

\section{Species responsible for strain-aging in NiAl}

A preliminary determination of the species most likely responsible for the strain-aging effects in $\mathrm{NiAl}$ can be made by examination of the aging behaviors of all eight alloys. Discontinuous yielding, in the form of yield points and yield plateaus, was observed in CPNiAl-1, CPNiAl-2, NiAl-100C, NiAl-300C and HPNiAl-C, while continuous yielding was observed in HP-NiAl, NiAl-Ti or NiAl-N following heat treatments known to produce yield points in conventional cast and extruded $\mathrm{NiAl} .{ }^{19}$ In $\mathrm{NiAl}-\mathrm{N}$, the oxygen and nitrogen contents were much higher than those observed in CPNiAl-1 or CPNiAl-2 while the C-content was much lower, which suggests that nitrogen and oxygen are not the species responsible for the observed yield points. When all excess interstitials were reduced sufficiently, as in the case of HP-NiAl, no yield points were observed; however, doubling the carbon concentration ( $\mathrm{HPNiAl}-\mathrm{C}$ ) resulted in a well-defined yield point. These observations are supported by the prior investigations of Noebe and $\mathrm{Garg}^{24}$ who observed sharp yield points in powder processed conventional purity $\mathrm{NiAl}(\mathrm{C}=143$ appm, $\mathrm{O}=227$ appm, and $\mathrm{N}=6$ appm) but no yield points in powder processed nitrogen-doped $\mathrm{NiAl}(\mathrm{C}=57$ appm, $\mathrm{O}=347$ appm, and $\mathrm{N}=904 \mathrm{appm}$ ). Also, in HPNiAl-C, it was observed ${ }^{12,13}$ that longer aging times are required to achieve the same yield increment as observed in CPNiAl-1 and CPNiAl-2. It is believed that this behavior is a result of the significant reduction in the concentrations of interstitials, particularly C. Since there is less carbon to pin dislocations in $\mathrm{NiAl}-\mathrm{C}$, the carbon present must, presumably, diffuse longer distances to cause pinning. Finally, in $\mathrm{NiAl}-\mathrm{Ti}$, the bulk interstitial levels were equivalent to those observed in $\mathrm{CP}$ NiAl-2 which exhibited yield point behavior. However, no yield points were observed in NiAl-Ti which was shown to contain $\mathrm{TiC}$ precipitates; this suggests that the lack of a yield point in NiAl-Ti is due to the gettering of sufficient carbon from the NiAl matrix and that carbon is the species responsible for the observed yield points.

\section{Influence of prestraining}

As noted in the Results, the return of a sharp yield point is much more rapid when the specimen has been prestrained uniaxially as opposed to hydrostatically. During uniaxial deformation of $\mathrm{NiAl}$, dislocations cross-slip easily forming cell structures ${ }^{24,26,28-30}$ that result in high work hardening rates at room temperature. As a result, the dislocations are in essence pinned. In contrast, samples pressurized hydrostatically show a more even distribution of dislocations which are not bound in cells (Fig. 11 and ref. 21). In uniaxially prestrained samples, since some of the dislocations are already locked up in cell structures, fewer mobile dislocations are available. Thus, less solute is required to pin the available mobile dislocations. Since more mobile dislocations are available in hydrostatically prestrained samples, more carbon 
is required to cause pinning. As a result, longer aging times are required to achieve the same yield point increments observed after uniaxial prestraining. A similar explanation has been applied to strain-aged steels prestrained in directions nonparallel to the original tensile direction. ${ }^{31}$

The results of this study also revealed a further reduction in the yield stress of CPNiAl-1, HP$\mathrm{NiAl}$, and $\mathrm{HPNiAl}-\mathrm{C}$ following pressurization to $1.4 \mathrm{GPa}$. However, no such effect was observed in NiAl-N. Prior investigations by Margevicius et $a l^{21}$ on pressurized $\mathrm{NiAl}$ alloys have shown that dislocation generation is enhanced by compositional differences between neighboring grains. This suggests that higher dislocation densities will be induced in CPNiAl-1, HP-NiAl, and HPNiAl-C over NiAl-N due to the larger compositional variations between the neighboring grains as a result of the casting process.

Despite its influence on the tensile flow behavior of NiAl alloys, prestraining, whether uniaxial or hydrostatic, had no observable influence on the tensile ductility and fracture behavior of NiAl. In $\mathrm{CP}-\mathrm{NiAl}$, for example, the fracture surfaces were approximately $37 \%$ intergranular regardless of how the specimens were prestrained or strain aged prior to testing. In HP-NiAl, however, there was an apparently higher propensity for intergranular fracture over transgranular failure. Interestingly, this alloy, although apparently closer to stoichiometry and free from high interstitial levels, exhibited lower tensile ductilities than the CP-NiAl and the $\mathrm{NiAl}-\mathrm{N}$ alloys. This observation contradicts the observations in single crystals where soft-oriented specimens having low interstitial levels and high purity were shown to exhibit nearly $5 \%$ tensile ductility at room temperature, regardless of pretest treatments. ${ }^{22}$ Although some of these observations can be related to the differences in grain size between the alloys, ${ }^{32}$ a more thorough investigation of these issues are required.

\section{CONCLUSIONS}

The yield points observed in conventional purity and carbon-doped $\mathrm{NiAl}$ are the result of strong dislocation pinning by interstitial carbon. Oxygen and nitrogen levels as high as 0.035 and 0.09 at $\%$, respectively, do not appear to pin dislocations in $\mathrm{NiAl}$ and, therefore, do not produce yield point phenomena.

Hydrostatic prestraining as opposed to uniaxial prestraining delays the kinetics of the yield point return by forming random networks of free unpinned dislocations which require more diffusion time for strong locking to occur.

Yield point phenomena can be removed by microalloying with sufficient levels of reactive elements such as $\mathrm{Ti}$, which getters carbon from the matrix by forming precipitates of $\mathrm{TiC}$.

Despite their influence on the flow behavior of $\mathrm{NiAl}$, prestraining and/or strain-aging have no observable impact on the room-temperature fracture characteristics of $\mathrm{NiAl}$ alloys. In fact, fracture always occurs by a mixture of intergranular failure and transgranular cleavage and tensile ductility was unaffected by the various prestrain and annealing treatments performed.

\section{ACKNOWLEDGEMENTS}

Helpful discussions with R. E. Reed-Hill are gratefully acknowledged. J. J. L. was supported by the Office of Naval Research and the National Science Foundation under Grants ONR-N0001491-J-1370 and NSF-DMR-89-8326. M. L. W. and M. J. K. express their appreciation for the financial and technical support of the NASA-Lewis Research Center under grant number NGT3-2958.

\section{REFERENCES}

1. Noebe, R. D., Bowman, R. R. \& Nathal, M. V., Int. Mater. Rev., 38 (1993) 193.

2. Pascoe, R. T. \& Newey, C. W. A., Metall. Sci. J., 5 (1971) 50 .

3. Hack, J. E., Brzeski, J. M. \& Darolia, R., Mater. Sci. Eng., A192/193 (1995) 268.

4. Hack, J. E., Brzeski, J. M., Darolia, R. \& Field, R. D., High-Temperature Ordered Intermetallics $V$, Eds I. Baker, R. Darolia, J. D. Whittenberger \& M. H. Yoo, Materials Research Society, vol. 288, Pittsburgh, PA, 1993, p. 1197.

5. Lautenschlager, E. P., Kiewit, D. A. \& Brittain, J. O. Trans. Metall. Soc. AIME, 233 (1965) 1297.

6. Margevicius, R. W. \& Lewandowski, J. J., Scripta Metall. Mater., 25 (1991) 2017.

7. Field, R. D., Lahrman, D. F. \& Darolia, R., High-Temperature Ordered Intermetallic Alloys $V$, Eds I. Baker, R. Darolia, J. D. Whittenberger \& M. H. Yoo, Materials Research Society, vol. 288, Pittsburgh, PA, 1993, p. 423.

8. Brzeski, J. M., Hack, J. E., Darolia, R. \& Field, R. D., Mater. Sci. Eng., A170 (1993) 11.

9. Liu, C. T., Lee, E. H., George, E. P. \& Duncan, A. J., Scripta Metall. Mater, 30 (1994) 387.

10. Pascoe, R. T. \& Newey, C. W. A., Metall. Sci. J., 2 (1968) 138.

11. Brzeski, J. M., Hack, J. E. \& Darolia, R., High-Temperature Ordered Intermetallic Alloys VI, Eds J. A. Horton, I. Baker, S. Hanada, R. D. Noebe and D. S. Schwartz, Materials Research Society, vol. 364, Pittsburgh, PA, 1995 , p. $41 \dot{9}$.

12. Weaver, M. L., Kaufman, M. J. \& Noebe, R. D., Intermetallics, 4 (1996) 121. 
13. Weaver, M. L., Noebe, R. D., Lewandowski, J. J., Oliver, B. F., \& Kaufman, M. J., Mater. Sci. Eng., A192/193, (1995) 179.

14. Weaver, M. L., Levit, V. Kaufman, M. J. \& Noebe, R. D., High-Temperature Ordered Intermetallic Alloys VI. Eds. J. A. Horton, I. Baker, S. Hanada, R. D. Noebe \& D. S. Schwartz, Materials Research Society, vol. 364, Pittsburgh, PA, 1995, p. 425.

15. Weaver, M. L., Investigation of Strain Aging in the Ordered Intermetallic Compound $\beta-\mathrm{NiAl}, \mathrm{Ph} . \mathrm{D}$. Dissertation, University of Florida, 1995.

16. Weaver, M. L., Noebe, R. D. \& Kaufman, M. J., Metall. Mater. Trans. A (1996 in press).

17. Kitano, K. \& Pollock, T. M., Structural Intermetallics, Eds R. Darolia, J. J. Lewandowski, C. T. Liu, P. L. Martin, D. B. Miracle and M. V. Nathal, The Minerals, Metals and Materials Society, Warrendale, PA, 1993, p. 591.

18. Kitano, K., Pollock, T. M. \& Noebe, R. D., Scripta Metall. Mater., 31 (1994) 397.

19. Margevicius, R. W., Lewandowski, J. J., Locci, I. E. \& Noebe, R. D., Scripta Metall. Mater., 29 (1993) 1309.

20. Margevicius, R. W. \& Lewandowski, J. J., Acta Metall. Mater., 41 (1993) 485.

21. Margevicius, R. W., Lewandowski, J. J. \& Locci, I. E., Structural Intermetallics, Eds R. Darolia, J. J. Lewandowski, C. T. Liu, P. L. Martin, D. B. Miracle \& M. V. Nathal, The Minerals, Metals and Materials Society, Warrendale, PA, 1993, p. 577.
22. Johnson, D. R., Joslin, S. M., Oliver, B. F., Noebe, R. D. \& Whittenberger, J. D., First International Conference on Processing Materials for Properties, Eds H. Henein \& T. Oki, TMS, Warrendale, PA, 1993 p. 865.

23. Reviere, R. D., Oliver, B. F. \& Bruns, D. D., Mater. Manuf. Proc., 4 (1989) 103.

24. Noebe, R. D. \& Garg, A., Scripta Metall. Mater., 30 (1994) 815 .

25. Margevicius, R. W. \& Lewandowski, J. J., Metall. Mater. Trans. A, 25A (1994) 1457.

26. Kim, J. T., Noebe, R. D. \& Gibala, R., Proceedings of the International Symposium of Intermetallic Compounds - Structural and Mechanical Properties, Ed, O. Izumi, Japan Institute of Metals, Sendai, Japan, 1991, p. 591.

27. Bowman, R. R. \& Noebe, R. D., Superalloys 1992, Eds S. D. Antolovich, R. W. Stusrud, R. A. MacKay, D. L. Anton, T. Khan, R. D. Kissinger \& D. L. Klarstrom, The Minerals, Metals \& Materials Society, Warrendale, PA, 1992 p. 341.

28. Nagpal, P. \& Baker, I., J. Mater. Let., 11 (1992) 1209.

29. Nagpal, P., Baker, I. \& Horton, J. A., Intermetallics, 2 (1994) 23.

30. Bowman, R. R., Noebe, R. D., Raj, S. V. \& Locci, I. E., Metall. Trans., 23A (1992) 1493.

31. Wilson, D. V. \& Ogram, G. R., JISI, 206 (1968) 911.

32. Weaver, M. L., unpublished research, University of Florida/NASA-Lewis Research Center, 1995. 